\title{
Is the Feeling of Unity That Kant Identifies in his Third Critique a Type of Inexpressible Knowledge?
}

\author{
A.W. MOORE
}

\begin{abstract}
Kant, in his third Critique, confronts the issue of how rule-governed objective judgement is possible. He argues that it requires a particular kind of aesthetic response to one's experience. I dub this response 'the Feeling of Unity', and I raise the question whether it is a type of inexpressible knowledge. Using David Bell's account of these matters as a touchstone, I argue that it is.
\end{abstract}

1. My starting point is a splendid essay by David Bell entitled 'The Art of Judgement', 1 in which he addresses the very basic, very Kantian question, 'How is rule-governed objective judgement possible?' One of Bell's aims is to investigate the way in which, according to Kant, such judgement requires a spontaneous transformation of the manifold of intuition into something unified.

Bell's account, which seems to me to be both exegetically sound and philosophically very illuminating, is as follows. Kant's first Critique $^{2}$ is devoted in large part to an elucidation of what the required unity consists in and what its conditions are; an elucidation, in other words, of what we, who exercise rule-governed objective judgement, need somehow to procure. His third Critique ${ }^{3}$ is more concerned with how we manage to procure it. What is

1 David Bell, 'The Art of Judgement', Mind 96 (1987). (See also David Bell, 'Some Kantian Thoughts on Propositional Unity', Proceedings of the Aristotelian Society Supplementary Volume 75 (2001), §IV, for a very useful summary.) My essay is derived from a lecture that I gave at a conference in honour of David Bell at the University of Sheffield in July 2006. I am grateful to participants at that conference for their extremely helpful comments.

Immanuel Kant, Critique of Pure Reason, trans. and ed. Paul Guyer and Allen W. Wood (Cambridge: Cambridge University Press, 1998).

Immanuel Kant, Critique of the Power of Fudgement, trans. Paul Guyer and Eric Matthews and ed. Paul Guyer (Cambridge: Cambridge University Press, 2000). Note: both in the title given here and in all subsequent 


\section{A.W. Moore}

required of us, Kant argues, is a particular kind of aesthetic response to our experience. Rule-governed objective judgement needs to be grounded in non-rule-governed subjective judgement. It needs to be grounded in a feeling that certain elements of experience constitute an integral, satisfying whole. As Kant himself puts it in the title of $\$ 35$ of his third Critique, 'the principle of taste is the subjective principle of the power of judgement in general.'

The idea that rule-governed objective judgement needs to be grounded in non-rule-governed subjective judgement (which in turn needs no further grounding) blocks a regress that threatens to afflict our understanding of these matters, a regress recognized not only by Kant but also, as Bell indicates at an early stage in his essay and amplifies in some fascinating comparisons that he draws towards the end of it, ${ }^{4}$ by Wittgenstein. This threat arises from the thought that, in order to make any objective judgement in accordance with some rule, one must first make an objective judgement in accordance with some other rule, to determine how the first rule applies. Put like that, the thought is not particularly enticing: the regress is obvious. But the thought can also appear in much more attractive guises that make the regress altogether less obvious. Both Kant and Wittgenstein work hard at exposing the thought in these other guises. And both, in discussing what is really required of us if we are to make an objective judgement in accordance with some rule, use the metaphor of blindness. Kant says that we would not be able to make objective judgements at all without 'a blind though indispensable function of the soul. ${ }^{5}$ And Wittgenstein says, 'When I obey a rule, I do not choose.-I obey the rule blindly. ${ }^{\prime 6}$ As Bell reminds us, and as will be relevant again later, Kant also famously uses the metaphor of blindness in describing intuitions without concepts. ${ }^{7}$ And that helps to explain what both Kant and Wittgenstein are getting at: there is, grounding the exercise of concepts involved in making rule-governed objective

quotations from Kant I have inserted an 'e' in 'judgement' to conform with the spelling used in the rest of this essay.

Op. cit. note $1,226-227$ and $\$ 7$ respectively.

Op. cit. note 2, A78/B103.

6 Ludwig Wittgenstein, Philosophical Investigations, trans. G.E.M. Anscombe, revised edn (Oxford: Basil Blackwell, 1974), Pt I, §219, his emphasis.

Op. cit. note 2, A51/B75. 


\section{A Type of Inexpressible Knowledge?}

judgements, something that does not involve the exercise of concepts at all.

Bell conveys what Kant, in particular, is getting at-the aesthetic response indicated above, which I shall hereafter dub 'the Feeling of Unity's_by using the analogy of coming to make sense of a work of abstract expressionism. ${ }^{9}$ This involves coming to feel that various aspects of the work 'belong indissoluably [sic] together': those aspects come 'to strike one as, in a quite particular way, right.' ${ }^{10}$ There is a whole swirl of philosophy here. We are reminded of Kant's own discussion, in the first Critique, of the way in which, through one's imagination, one can recognize a unity in one's sensory experience which allows for application of the very concept of an object. ${ }^{11}$ We are reminded of Wittgenstein's discussion, in Philosophical Investigations, of aspect recognition, one central example of which, mentioned there, is using one's imagination in such a way as to hear something as a variation on a given theme. ${ }^{12} \mathrm{We}$ are reminded of how two green things can seem to be fit objects of co-classification 'in a quite particular way' in which a green thing and a blue thing are not. ${ }^{13}$ Making sense of a work of art is a paradigm of that most quintessential and most pervasive of human activities, never far from the surface in any of Kant's or Wittgenstein's writings: making sense (more generally) of things. And making sense of things is certainly a precondition of making rule-governed objective judgements. On the view being canvassed, it is also fundamentally an exercise of the Feeling of Unity.

2. I have argued elsewhere that there is such a thing as inexpressible knowledge-knowledge which lacks content of the sort that can be expressed by a declarative, descriptive sentence-and that such knowledge, some of which enables whoever possesses it to make sense of things in a certain way, is required to ground any fully conceptual expressible knowledge. ${ }^{14}$ There are obvious parallels

8 This label is not meant to signal any special homogeneity: the Feeling of Unity has many disparate instances.

9 Op. cit. note $1, \S 5$.

10 Ibid., 237, his emphasis.

11 See ibid., 239-240, together with references given there.

12 Op. cit. note 6, 213; and, more generally, Pt II, §xi, passim. See also Kant, op. cit. note 3 , $\$ 35$, for the importance of imagination in Kant.

13 This is of course an allusion to the philosophical quagmire which is the concept of grueness: see Nelson Goodman, Fact, Fiction, and Forecast, $3^{\text {rd }}$ ed. (Brighton: The Harvester Press, 1979), esp. ch. III.

14 See esp. A.W. Moore, Points of View (Oxford: Oxford University Press, 1997), ch. 8. 


\section{A.W. Moore}

with the Kantian view outlined above. ${ }^{15}$ The question I wish to address in this essay is whether there are grounds for assimilating the two views. Is the Feeling of Unity appropriately regarded as a type of inexpressible knowledge? ${ }^{16}$

Here is one reason for answering this question negatively. Kant, when discussing how the power of judgement must have a capacity for being exercised in a non-rule-governed way, as well as a capacity for being directed by rules, describes that power as 'a special talent that cannot be taught but only practised'. ${ }^{17}$ Talk of knowledge, on the other hand-even talk of inexpressible knowledge - suggests (if it does not entail) something that can be taught.

I do not find this reason compelling however. First, 'suggests' is the operative word. And second, there are in any case grounds for thinking that, in the passage cited, Kant is presupposing a restricted, rule-based conception of teaching. If he is, then he need not balk at the idea that the talent of which he speaks can be instilled by other kinds of teaching — or, as we might more naturally say, by kinds of training. ${ }^{18}$ For my own part, I see no reason to preclude the possibility of teaching in a case of this kind. Something that Wittgenstein says seems to me entirely apt:

Can someone else be a man's teacher in this? Certainly. From time to time he gives him the right tip.- This is what 'learning' and 'teaching' are like here.-What one acquires here is not a technique; one learns correct judgements. There are also rules, but. . only experienced people can apply them right. ${ }^{19}$

Here is a second reason for answering my question negatively. This reason complements the first. The first was targeted at the idea that the Feeling of Unity can properly be called knowledge. The second is targeted at the idea that it can properly be called inexpressible. The worry about calling the Feeling of Unity inexpressible is that it issues in judgements. True, it issues in subjective judgements,

15 Unsurprisingly! I acknowledge the influence of Kant in ibid., 186, note 13 .

16 Somewhat more precisely, are instances of the Feeling of Unity appropriately regarded as states of inexpressible knowledge?

Op. cit. note 2, A133/B172. Note: 'practised' was originally spelt with a 'c'; I have used the British spelling.

18 See Kant's own reference to training, and his discussion of examples, shortly after the material quoted in the previous footnote, in ibid., A134/ B173-174.

19 Op. cit. note 6, 277, his emphasis. Cf. Pt I, \$232. 


\section{A Type of Inexpressible Knowledge?}

which do not involve concepts. But they do involve what Kant is prepared to call predicates, and communicability is of their very essence. ${ }^{20}$

I do not find this reason compelling either. It underestimates how much is required for a state to be expressible. The sheer fact that a given state issues in judgements of a certain kind does not suffice. A state can issue in judgements that do not in any sense express its content, as when a state of irritation issues in a judgement to the effect that, unless someone stops doing something, there will be trouble. A fortiori the sheer fact that a state issues in judgements of the kind that Kant calls subjective does not suffice for it to be expressible. Such judgements may well lack what it takes, beyond superficial grammar, to count as expressing any content at all.

Next, here is a reason for answering my question affirmatively. We noted above Kant's use of the metaphor of blindness in characterizing that which enables us to make rule-governed objective judgements; and we also noted his use of that same metaphor in characterizing intuitions without concepts. If, as this suggests, the Feeling of Unity involves intuitions without concepts, then precisely what it is, one might think, is a type of inexpressible knowledge-since what it lacks, of that combination of intuitions and concepts that makes expressible knowledge possible, is the very element (the conceptual element) that allows such knowledge to be expressed. ${ }^{21}$ And there are several passages in the third Critique that seem to lend further support to the suggestion that the Feeling of Unity does involve intuitions without concepts. For instance, in $\$ 35$ (to which I referred earlier) Kant explicitly says that 'the judgement of taste differs from logical judgement in that the latter subsumes a representation under concepts of the object, but the former does not subsume under a concept at all.' 22 Later, in $\$ 49$, he introduces what he calls 'aesthetic ideas', intended to complement the 'ideas of reason' which have played such a significant rôle in the two earlier Critiques. ${ }^{23}$ Whereas an idea of reason is 'a concept to which no

On their involving predicates see op. cit. note $3, \S \S 36-37$; on their communicability see ibid., 5:217-218, 231-232, and 292-293; on the demands that Kant places on concepts see ibid., 5:174.

21 For an excellent discussion of Kant's attitude to intuitions without concepts, focusing primarily on his first Critique, see Lucy Allais, 'Kant's Account of Non-Conceptual Content' (unpublished).

22 Op. cit. note 3, 5:286.

23 See e.g. op. cit. note 2, A312-338/B368-396; and Immanuel Kant, Critique of Practical Reason, trans. Mary J. Gregor, in his Practical 


\section{A.W. Moore}

intuition. .. can be adequate', an aesthetic idea is a 'representation of the imagination' (by which Kant later indicates that he means an intuition) to which no concept can be adequate. ${ }^{24}$ And, as if in a deliberate attempt to bolster the suggestion that he is talking about inexpressible knowledge here, Kant goes on to say that 'no language fully attains [an aesthetic idea] or can make [it] intelligible.' 25

Unfortunately, this too is an unsatisfactory answer to my question. There are several considerations that can be brought against it. Some of these can be fairly easily countered. I shall mention two that can. But I shall also mention two that cannot.

The first consideration that can be fairly easily countered is this. Kant famously insists, in the very passage in which he says that intuitions without concepts are blind, that neither concepts without intuitions nor intuitions without concepts can yield knowledge. ${ }^{26}$

The reason why I say that this consideration can be fairly easily countered is that plausibly, in such contexts, Kant is presupposing a restricted conception of knowledge-as something that, even if it is not knowledge that this or that is the case, is at the very least expressible. ${ }^{27}$ (There is corroboration for this in the fact that, when discussing our use of ideas of reason, Kant does sometimes invoke a less restricted conception of knowledge, which includes what he calls practical knowledge. ${ }^{28}$ )

The second consideration that can be fairly easily countered is that the Feeling of Unity is indeed a feeling, not an intuition. Kant distinguishes between these. ${ }^{29}$

Philosophy, trans. and ed. Mary J. Gregor (Cambridge: Cambridge University Press, 1996), Pt One, Bk II, Ch. II, §VII.

24 Op. cit. note 3, 5:314, emphasis removed.

25 Ibid.

26 Op. cit. note 2, A50/B74. Note: the translations in the Cambridge Edition of the Works of Immanuel Kant render 'Erkenntnis' as 'cognition' rather than as 'knowledge', but nothing of philosophical substance hangs on my tacit departure from that, either here or elsewhere in this essay.

27 Expressible knowledge which is not knowledge that this or that is the case is 'tacit' knowledge: see Martin Davies, 'Tacit Knowledge and Subdoxastic States', in Alexander George (ed.), Reflections on Chomsky (Oxford: Basil Blackwell, 1989).

28 See e.g. op. cit. note 23, 5:103; and op. cit. note 3, 5:195.

29 Op. cit. note 3, 5:206. ('To understand the force of this passage, note that Kant counts intuitions as a kind of representation: see op. cit. note 2, A320/B376-377.) 


\section{A Type of Inexpressible Knowledge?}

But the suggestion above was that the Feeling of Unity involves intuitions of a certain sort, not that it consists of them, still less that it is one.

I now turn to the two considerations that are not so readily dealt with. First, if the Feeling of Unity does involve intuitions without concepts, this is not enough to sustain the proposed comparison with states of knowledge that involve both intuitions and concepts. The mere fact that the conceptual element in these states is what makes them expressible is no reason to expect intuitions without concepts to yield inexpressible knowledge. A sweet meringue is a mixture of egg whites and sugar; the sugar is what makes it sweet; yet egg whites on their own do not make bitter meringues.

Second, whether or not the Feeling of Unity involves intuitions without concepts, aesthetic ideas are something quite separate. They are more or less irrelevant to this issue. An aesthetic idea is what the imagination produces when it attempts to produce an intuition that is adequate to an idea of reason. 'Attempts' is the operative word. For an idea of reason is a concept to which no intuition can be adequate. However, the form that the attempt takes, whereby the imagination 'simulates the precedent of reason in attaining to a maximum', ${ }^{30}$ ensures that the intuition that results 'occasions much thinking though without it being possible for any determinate... concept to be adequate to it.' 31 That is to say, the attempt, by the imagination, to produce an intuition that is adequate to a concept to which no intuition can be adequate results in an intuition to which, conversely, no concept can be adequate. This in turn 'enlarges the concept itself in an unbounded way... and sets the faculty of intellectual ideas (reason) into motion.' 32 So it is as if there is a frenzy of activity in which imagination and reason are in some kind of absurd race to keep up with each other even though they are moving in different directions. There is much here of note, but very little that relates directly to the Feeling of Unity. ${ }^{33}$

30 Op. cit. note $3,5: 314$.

31 Ibid.

32 Ibid.

33 There are, however, some further connections with my own view which I want to take a brief digression to consider. This interplay between ideas of reason and aesthetic ideas is just the sort of thing that is liable to result from the (necessarily forlorn) attempt to express inexpressible knowledge, or at least inexpressible knowledge of a certain kind. I have in mind our knowledge of how to act in accord with what Kant calls regulative principles, or more specifically our knowledge of 


\section{A.W. Moore}

3. The matter remains unresolved then. Is there anything in Bell's essay that bears on it?

Yes: in fact Bell is quite explicit that the Feeling of Unity cannot be said to be either inexpressible or cognitive. ${ }^{34}$ However, we need to distinguish between the letter of his essay and the spirit. Concerning the question of expressibility, Bell draws a distinction between 'expression' and 'articulation' and concedes that the Feeling of Unity, even though it can be expressed, cannot be articulated. But what he means by 'articulation'-the saying of something 'in assertoric, descriptive language'-is just what I have been meaning by 'expression', whereas what he means by 'expression' is something wider whereby 'gestures ... and forms of behaviour can be said to express feelings and emotions.' ${ }^{35}$ So he takes the Feeling of Unity to be inexpressible in my terms. Whether he likewise takes the Feeling of Unity to be cognitive in

how to act as if ideas of reason applied within the sphere of possible experience (op. cit. note 2, A508-515/B536-543 and A669/B697 ff.), knowledge which I take to be, indeed, inexpressible. In attempting to express an item of knowledge of this kind, we are liable to say that the idea in question does so apply. And we are liable to exercise our imagination in an attempt to produce an intuition that is adequate to the idea; in other words we are liable to create an aesthetic idea. Suppose, for example, that we have inexpressible knowledge of how to act as if God is always at hand. And suppose that the attempt to express this results in our saying that God is always at hand (cf. ibid., A674/B702 ff.). Then we shall naturally try to 'picture' God as some ubiquitous Being. This will involve us in creating an aesthetic idea which will 'let [us] think more than [we] can express in a concept determined by words;... [and will serve the idea of God] by opening up for [the mind] the prospect of an immeasurable field of related representations', (op. cit. note 3, 5:315). (Cf. Gilles Deleuze, Kant's Critical Philosophy: The Doctrine of the Faculties, trans. Hugh Tomlinson and Barbara Habberjam (London: The Athlone Press, 1984), 57.) - Not that the connections between Kant's aesthetics and the attempt to express what cannot be expressed stop there. For what will make these various contrivances seem 'apt' for their respective (impossible) tasks is surely something like the Feeling of Unity: a feeling that certain concepts, intuitions, and linguistic items belong together and give life to one another; a feeling which is, in Kant's words, 'of much that is unnameable', and which, again in his words, 'animates the cognitive faculties and combines spirit with the mere letter of language', (op. cit. note $3,5: 316)$.

34 Op. cit. note 1, 243 and 239 respectively.

35 Ibid., 243. 


\section{A Type of Inexpressible Knowledge?}

my terms is less clear. But if, like Kant, he is working with a restricted conception of knowledge-as something which can be expressed, or, in Bell's own terms, articulated-then it is at least open to him to acknowledge a wider conception whereby the Feeling of Unity is cognitive as well.

4. My own view, which I shall now try to defend, is that the Feeling of Unity is indeed a type of inexpressible knowledge.

Every instance of the Feeling of Unity is an enabling state. To feel that certain elements of experience constitute an integral, satisfying whole is to be enabled to make rule-governed objective judgements. Still, while every state of knowledge is also an enabling state, not every enabling state is a state of knowledge. Consider, for instance, states of accidentally true belief, or indeed a state such as being able to lift a $1001 \mathrm{~b}$ weight. What more does it take for a state to be a state of knowledge? One thing it takes is location in-to use Sellars' famous phrase-'the logical space of reasons', ${ }^{36}$ where location in the logical space of reasons involves standing in rational relations to other occupants of that same space. (The entities located in the logical space of reasons are an utter miscellany. They include beliefs, desires, choices, intentional actions, and many more besides. Even so, they do not include a state of being able to lift a $1001 \mathrm{~b}$ weight. A non-rational being can be in a state of that kind. And it makes no sense to ask what reason someone has for being able to lift a $100 \mathrm{lb}$ weight, nor what being able to lift a $100 \mathrm{lb}$ weight gives the person a reason to do.) What about instances of the Feeling of Unity? Do they have a place in the logical space of reasons? It seems to me that they do. This is not just because they are available only to rational beings, but also because of what they enable rational beings to do, which is, first and foremost, to negotiate that very space. The fact that I have a grasp, through exercise of the Feeling of Unity, of what green things have in common enables me to make judgements about green things, which in turn enables me to communicate with others who make such judgements, to learn from what they tell me, to arrive at various beliefs about green things, and in countless other ways to reposition myself in the logical space of reasons. The Feeling of Unity provides me and other people with shared ways of making sense of things, and it does this by enabling us to bring what we are given in experience under the unity of various shared

36 Wilfrid Sellars, 'Empiricism and the Philosophy of Mind', reprinted in his Science, Perception and Reality (London: Routledge \& Kegan Paul, 1963), 169. 


\section{A.W. Moore}

concepts. Its instances, furthermore, can have reasons. For there can be better and worse ways of making sense of things-which means that there can be reasons for exercising the Feeling of Unity in some ways rather than others. (To say that one way of making sense of things is 'better' than another is not to say that it is 'right' and the other 'wrong'. There is no question of right or wrong here. 'Better' in this context means something like 'more useful'. Its application is relative to an individual and to a set of circumstances. And, as I just intimated, whether one way of making sense of things is more useful than another to me, surrounded as I am by other people who make sense of things in the ways they do, depends in part on what will facilitate communication between us.) Given all of this, and assuming that there is nothing here to suggest an assimilation of the Feeling of Unity to an accidentally true belief, I think that there is enough to warrant our giving it the title of knowledge. ${ }^{37}$

But does this have any grounding in ordinary usage? I have mooted reasons of a general kind for why the Feeling of Unity should be classified as a type of knowledge; but I have done nothing to indicate how any particular instance could be characterized as such, still less to indicate how it could be idiomatically characterized as such. In fact, however, this is not difficult. I talked above about my grasp of what green things have in common. I could just as well have talked about my knowledge of what green things have in common; or about my knowledge of what it is for something to be green; or indeed about my knowledge of how to exercise the concept of greenness. There is a grounding in ordinary usage. I conclude that the Feeling of Unity is a type of knowledge.

But inexpressible knowledge? Well, yes. Instances of this feeling are not representations of how things are. They have no content. Or at least, they do not have content of the kind that could be expressed in a declarative, descriptive sentence. This is connected with the fact that they do not themselves involve the exercise of concepts. (Knowing how to exercise the concept of greenness does not involve actually doing so.) Thus even if I am right that they have a place in the logical space of reasons, they nevertheless lack what is surely the paradigmatic feature of states that occupy that space. But to whatever extent this is paradoxical, it is only a variation on the paradox of blind rationality which Bell considers in his essay, a paradox which he in turn relates to Kant's claim that the imagination exhibits both freedom and conformity to

37 I am here summarizing views that I have defended elsewhere: see op. cit. note 14 , ch. 8 . 


\section{A Type of Inexpressible Knowledge?}

law. ${ }^{38}$ Inexpressible knowledge exhibits just that same interplay of opposed features, precisely what equips it to fulfil its own unique rôle in grounding other, more characteristic occupants of the logical space of reasons.

I conclude that the Feeling of Unity is a type of inexpressible knowledge. And I would like to think that, despite the letter of Bell's essay, which does not allow the Feeling of Unity to be characterized either as inexpressible or as knowledge, there is enough convergence in the spirit of his essay for him, under a suitable interpretation, to agree.

St Hugh's College, Oxford 